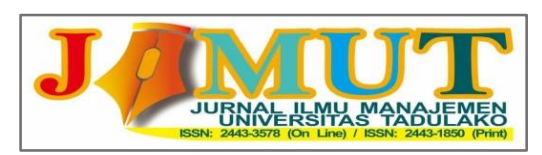

Vol. 6, No.3, September 2020, 222-231

\title{
PENGARUH KUALITAS MAKANAN TERHADAP KESETIAAN PELANGGAN KEDAI OISHI NADISHA DI KOTA PALU
}

\author{
Putri Listiani, Zakiyah Zahara \\ Program Studi S1 Jurusan Manajemen, Fakultas Ekonomi dan Bisnis, Universitas Tadulako \\ email: putrilistiani51@yahoo.co.id;zakiyah66.zm@gmail.com
}

\begin{abstract}
This study discusses food quality towards customer loyalty at Kedai Oishi Nadisha in Palu City In this study a sample of 100 respondents was taken. Sampling using purposive sampling is a determination of the sample Based on consideration, namely anyone who agrees with certain considerations or meets specific criteria that have been determined. The analytical model used in this study is a multiple linear regression analysis model. The results showed that simultaneously taste variables, presentation methods, and menu variation variables had a significant effect on the customer loyalty Kedai Oishi Nadisha.in Palu City, with a sig-F value of $0.00<a 0.05$. When compared with with the three variables, namely taste variables, presentation methods and menu variants. The most dominant variable influences is the taste variable and presentation method with the same number that is 0.252 for the significant value of taste variable that is equal to 0.005 and for the significant value of the presentation method variable and menu variation variable that is equal to 0.003 .
\end{abstract}

Keywords: Food Quality, Taste, Presentation Method, Menu Variation, Customer Loyalty.

\begin{abstract}
Abstrak
Penelitian ini bertujuan untuk mengetahui pengaruh kualitas makanan terhadap kesetiaan pelanggan pada Kedai Oishi Nadisha di Kota Palu. Dalam penelitian ini diambil sampel sebanyak 100 responden. Pengambilan sampel dengan menggunakan purposive sampling yaitu penentuan sampel secara kebetulan, dan siapa saja pertimbangan tertentu atau memenuhi kriteria khusus yang telah ditetapkan. Model analisis yang digunakan dalam penelitian ini adalah model analisis regresi linear berganda. Hasil penelitian menunjukkan bahwa secara serempak variabel cita rasa, variabel cara penyajian, dan variabel variasi menu berpengaruh signifikan terhadap kesetiaan pelanggan Kedai Oishi Nadisha di Kota Palu, dengan nilai sig- $F$ sebesar $0,00<0,05$. Apabila dibandingkan dengan ketiga variabel yaitu variabel cita rasa, cara penyajian dan variasi menu. Variabel yang paling dominan mempengaruhi adalah variabel cita rasa dan variabel cara penyajian dengan angka yang sama yaitu 0.252 untuk nilai signifikan variabel cita rasa yaitu sebesar 0.005 dan untuk nilai signifikan variabel cara penyajian dan variabel variasi menu yaitu sebesar 0.003 .
\end{abstract}

Kata Kunci: Kualitas Makanan, Cita Rasa, Cara Penyajian, Variasi Menu, Kesetiaan Pelanggan.

\section{PENDAHULUAN}

Globalisasi merupakan sebuah kenyataan yang tak bisa di pungkiri dan harus diterima oleh setiap orang di seluruh dunia, yang dimana negara-negara dan kebudayaan lokal akan hilang diterpa oleh kebudayaan dan ekonomi global, hal ini menuntut masyarakat untuk mengikuti setiap perubahan sekecil apapun yang telah terjadi, baik dari segi teknologi, komunikasi bahkan perubahan gaya hidup seseorang dalam mengkonsumsi makanan saat ini. Makanan khas dari suatu daerah tertentu mempunyai daya tarik tersendiri dan unik, sehingga setiap konsumen ingin mencoba sesuatu yang unik itu, salah satunya adalah restoran Jepang. Salah satu daerah yang menjadi tempat berkembangnya restoran Jepang di Indonesia adalah Kota Palu. Kedai Oishi Nadisha merupakan salah satu dari usaha restoran makanan Jepang yang ada di Kota Palu, kehadiran Kedai Oishi Nadisha ini bertujuan untuk memenuhi kebutuhan dan keinginan konsumen yang berada di Kota Palu dengan 


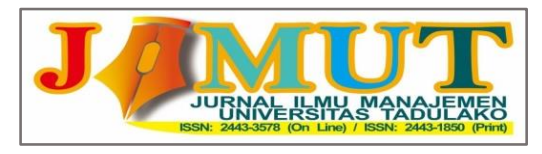

Vol. 6, No.3, September 2020, 222-231

cara menjual makanan khas Jepang yang telah dipadukan antara cita rasa makanan Jepang yang bercita rasa manis, asam, dan asin, dan cita rasa makanan di Kota Palu yang berbumbu komplit. Kedai Oishi Nadisha selalu mempertahankan kualitas makanan, agar cita rasa dari menu yang ditawarkan tetap konsisten.

Menurut Knight dan Kotschevar (2000:16) kualitas makanan sebuah konsistensi kualitas menu yang dicapai dengan penetapan suatu standar produk dan kemudian mengecek setiap poin-poin yang harus dikontrol untuk melihat kualitas yang ingin dicapai dalam kurun waktu yang telah ditetapkan. Menurut Winata dan Gienardy (2013:535) untuk mengukur kualitas makanan digunakan 3 (tiga) variabel yaitu: cita rasa, cara penyajian, dan variasi menu. Kedai Oishi Nadisha selalu mempertahankan kualitas makanan baik dari segi cita rasa, cara penyajian sehingga membuat pelanggan mempunyai rasa kesetiaan untuk datang dan melakukan pembelian kembali di Kedai Oishi Nadisha. Kesetiaan pelanggan merupakan hal yang sangat penting yang berhubungan dengan pengembangan usaha dalam bidang apapun, pelanggan yang mempunyai kesetiaan yang tinggi akan selalu menggunakan produk atau jasa yang telah disediakan oleh pelaku bisnis, tidak akan mudah terpengaruh dari produk atau jasa yang ditawarkan pihak lain yang sejenis, dan ketika terdapat hal-hal yang tidak mereka sukai, mereka akan memberitahukan kepada penyedia produk atau jasa tanpa tidak memberitahukannya kepada pihak lain.

Berdasarkan latar belakang yang telah dipaparkan di atas maka peneliti tertarik untuk meneliti tentang kualitas makanan, peneliti akan meneliti tentang "Pengaruh Kualitas Makanan Terhadap Kesetiaan Pelanggan Kedai Oishi Nadisha di Kota Palu". Rumusan masalah dalam penelitian ini yaitu untuk mengetahui dan menganisis:

1. Pengaruh kualitas makanan yang terdiri dari cita rasa, cara penyajian, dan variasi menu berpengaruh terhadap kesetiaan pelanggan pada Kedai Oishi Nadisha di Kota Palu.

2. Pengaruh cita rasa terhadap kesetiaan pelanggan pada Kedai Oishi Nadisha di Kota Palu.

3. Pengaruh cara penyajian terhadap kesetiaan pelanggan pada Kedai Oishi Nadisha di Kota Palu.

4. Pengaruh variasi menu terhadap kesetiaan pelanggan pada Kedai Oishi Nadisha di Kota Palu.

\section{KAJIAN LITERATUR DAN PENGEMBANGAN HIPOTESIS Pemasaran}

Pemasaran menurut Kotler dan Keler (2008:5) merupakan suatu proses sosial yang dinamis dan cepat dimana individu atau kelompok mendapatkan apa yang mereka butuhkan serta inginkan dengan cara membuat, menawarkan produk atau jasa yang mempunyai nilai dengan orang lain dan serta secara bebas dapat dipertukarkan.

\section{Manajemen Pemasaran}

Manajemen pemasaran menurut Laksana (2004:5) yaitu pertukaran produk atau jasa yang dilakukan melalui beberapa rangkaian aktifitas serta bauran pemasaran seperti produk, harga, iklan, dan lokasi.

\section{Pengertian Kualitas}

Kualitas menurut Feigenbaum (1996:6) yaitu gabungan karakteristik dari produk atau jasa yang dipasarkan melalui rekayasa pemasaran, pembuatan, dan pemeliharaan yang bisa membuat produk dan jasa yang digunakan dapat memenuhi impian pelanggan.

\section{Kualitas Makanan}

Kualitas makanan menurut Knight dan Kotschevar (2000:16) merupakan suatu tingkatan dalam konsistensi kualitas menu yang dicapai dengan penetapan suatu standar produk dan kemudian 


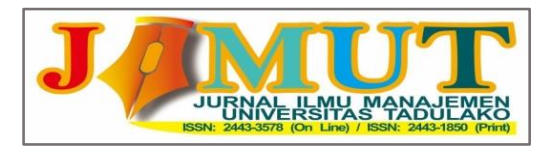

Vol. 6, No.3, September 2020, 222-231

mengecek setiap poin-poin yang kemudian dikontrol untuk melihat kualitas yang ingin dicapai dalam kurun waktu yang telah ditetapkan. Adapun hal-hal yang harus diperhatikan dalam menjaga kualitas makanan menurut menurut Winata dan Gienardy (2013:535) yaitu:

1. Cita Rasa

Cita rasa yaitu atribut dari sebuah makanan yang disajikan, dalam hal ini meliputi: penampakan, bau, rasa, tekstur, dan suhu. Cita rasa bisa dirasakan dan dinilai oleh manusia karena adanya bentuk kerja sama dari kelima macam indra yang dimiliki manusia.

2. Cara Penyajian

Cara penyajian makanan bisa dikatakan sebagai bentuk kreatifitas atau ide seseorang yang dilakukan pada proses akhir dalam penyajian makanan.

3. Variasi Menu

Variasi menu adalah perbedaan yang sengaja diciptakan atau dibuat untuk memberi kesan yang baru. variasi sangatlah diperlukan, variasi menu bertujuan untuk selalu menawarkan hal yang baru agar pelanggan tidak jenuh dengan menu makanan yang hanya itu-itu saja.

\section{Kesetiaan Pelanggan}

Oliver yang dikutip Hurriyati (2005:129) kesetiaan pelanggan yaitu pelanggan yang bertahan dengan komitmen yang dimiliki secara mendalam untuk tetap berlangganan secara konsisten di masa yang akan datang, meskipun terdapat pengaruh situasi dan usaha-usaha pemasaran mempunyai potensi untuk merubah komitmen pelanggan. Pelanggan yang setia memiliki 4 (empat) ciri yaitu:

1. Melakukan pembelian secara teratur.

2. Membeli diluar lini produk/jasa.

3. Merekomendasikan produk kepada orang lain.

4. Menunjukan kekebalan dari daya tarik produk sejenis dari pesaing

\section{Hubungan antara Kualitas Makanan dan Kesetiaan Pelanggan}

Kualitas makanan merupakan suatu kondisi yang menjadi tolak ukur penilaian pelanggan, produk yang dimaksud dalam hal ini yaitu makanan. Makanan yang berkualitas dapat membentuk kesetiaan pelanggan, semakin berkualitas produk dan jasa yang diberikan maka dapat menimbulkan keuntungan bagi usaha tersebut. Menurut Oakland dalam Wahyuni, dkk (2015:5) kualitas yakni pemenuhan kebutuhan konsumen, kualitas seringkali digunakan untuk menandai keunggulan suatu produk barang atau jasa, dengan terus-menerus menciptakan barang atau jasa sesuai dengan apa yang pelanggan butuhkan.

\section{METODE PENELITIAN}

Jenis penelitian deskriptif kausal yang artinya dilakukan untuk mendapatkan gambaran tentang penelitian yang berkaitan dengan kualitas makanan terhadap kesetiaan pelanggan di Kedai Oishi Nadisha. Objek penelitian ini yaitu Kedai Oishi Nadisha beralamat di Jalan Kijang Utara No.3B. Dalam penelitian ini responden yang digunakan adalah pelanggan di Kedai Oishi Nadisha di Kota Palu. Jenis data yang digunakan penelitian ini yaitu data kuantitatif yang diolah dari hasil kuesioner yang dibagikan kepada pelanggan di Kedai Oishi Nadisha. Populasi dalam penelitian ini jumlahnya tidak dapat diketahui. Adapun yang akan menjadi sampel dalam penelitian ini harus berdasarkan karakteristik yaitu sebagai berikut:

1. Pelanggan di Kedai Oishi Nadisha.

2. Sudah minimal 2 kali membeli dan berkunjung kembali. 


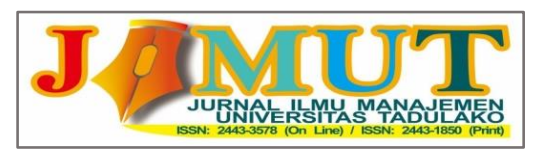

Vol. 6, No.3, September 2020, 222-231

3. Responden yang berusia lebih dari 17 tahun keatas (di asumsikan mampu memahami setiap item pertanyaan).

Menurut Roscoe (Research Methods For Business) dalam Kurniawan (2014:85) penentuan sampel, yaitu jumlah anggota sampel minimal 10 di kali dari jumlah variabel yang diteliti. Penelitian ini menggunakan sebanyak 25 di kali dari jumlah variabel penelitian, penelitian ini terdiri dari 4 variabel (3 variabel bebas +1 variabel terikat), maka jumlah sampel secara keseluruhan $25 \mathrm{X} 4=$ 100. Penentuan sampel penelitian sebesar 100 orang responden tersebut, sudah dianggap bisa mewakili keseluruhan populasi pelanggan di Kedai Oishi Nadisha. Teknik penarikan sampel yang digunakan penulis dalam menentukan keseluruhan sampel (responden) penelitian adalah purposive sampiling.

\section{Definisi Operasional Variabel}

Untuk menjelaskan variabel yang akan diteliti, maka perlu penjabaran definisi operasional dari masing-masing variabel yaitu sebagai berikut:

1. Cita rasa yaitu atribut dari sebuah makanan yang disajikan, dalam hal ini meliputi: penampakan, bau, rasa, tekstur, dan suhu. Cita rasa bisa dirasakan dan dinilai oleh manusia karena adanya bentuk kerja sama dari kelima macam indra yang dimiliki manusia. Indikator yang digunakan sebagai berikut:

a. Tampilan makanan yang menarik.

b. Potongan makanan yang menggugah selera.

c. Aroma makanan berbau sedap saat dihidangkan.

d. Rasa makanan yang disajikan sesuai dengan kriteria makanan.

e. Tekstur yang nyaman saat dikunyah.

f. Kesesuaian suhu dengan kriteria makanan.

2. Cara penyajian yaitu bentuk kreatiifitas atau ide seseorang yang dilakukan pada proses akhir dalam penyajian makanan, yang biasanya digunakan warna yang kemudian disusun secara menarik agar dapat menambah selera makan. Indikator yang digunakan sebagai berikut:

a. Terdapat perpaduan warna yang menarik di makanan sehingga menambah selera makan.

b. Makanan yang dihidangkan tertata rapi.

c. Terdapat hiasan (Garnish) dalam penyajian makanan yang memberikan kesan keindahan pada makanan yang disajikan.

d. Menggunakan wadah penyajian makanan sesuai dengan kondisi makanan.

e. Menggunakan alat saji yang sesuai dengan makanan (sushi menggunakan sumpit, dan ramen menggunakan sendok).

3. Variasi menu yaitu suatu perubahan yang ditujukan agar membuat sesuatu tidak membosankan. Variasi dapat berbentuk perbedaan yang sengaja diciptakan atau dibuat untuk memberi kesan yang baru. Indikator yang digunakan sebagai berikut:

a. Tersedia sushi dengan variasi di goreng.

b. Tersedia sushi dengan berbagai macam variasi isian yaitu: sosis, daging ayam, tuna, crab/kepiting, udang, daging sapi, abon ayam, dan abon sapi.

c. Tersedia sushi dengan variasi tambahan keju.

d. Tersedia sushi dengan variasi rasa pedas.

e. Tersedia ramen dengan berbagai macam variasi yaitu: bakso seafood, tuna pedas, udang, kepiting, daging ayam, sosis, dan keju.

f. Tersedia variasi menu ramen yang menyediakan tingkat kepedasan level 1 sampai dengan 5 (tidak pedas, sedikit pedas, pedas sedang, lumayan pedas, dan sangat pedas). 


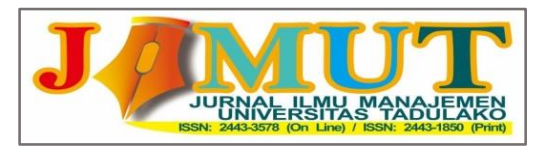

Vol. 6, No.3, September 2020, 222-231

g. Terdapat kandungan gizi yang beragam disetiap makanan yang ditawarkan.

4. Kesetiaan pelanggan merupakan suatu komitmen seseorang dalam melakukan pembelian produk yang berulang ditempat atau merek yang sama tanpa memperdulikan kondisi dan usaha tempat lain. Indikator yang digunakan sebagai berikut:

a. Melakukan pembelian secara teratur.

b. Pembelian diluar lini produk atau jasa.

c. Merekomendasikan produk kepada orang lain.

d. Menunjukan kekebalan dari daya tarik produk sejenis dari pesaing.

\section{Analisis Regresi Linear Berganda}

Analisis ini ditujukan untuk mengukur dugaan pengaruh faktor bebas terhadap faktor terikat, maka alat analisis yang dinilai tepat untuk digunakan adalah regresi linear berganda. Model umum bentuk persamaan alat analisis statistik parametrik regresi linear berganda (multiple regression linier), bisa digambarkan sebagai berikut. Sugiyono (2014:277).

$Y=\alpha+b_{1} X_{1}+b_{2} X_{2}+\ldots \ldots \ldots+b_{n} X_{n}$

Bila perumusan matematis regresi linier berganda diaplikasikan dalam penelitian ini, maka akan diperoleh bentuk persamaan sebagai berikut:

$Y=\alpha+\mathrm{b}_{1} X_{1}+\mathrm{b}_{2} X_{2}+\mathrm{b}_{3} X_{3}$

Dimana :

Y : Kesetiaan Pelanggan

$\alpha \quad$ : Konstanta

$\mathrm{b}_{1}-\mathrm{b}_{3} \quad$ : Koefisien regresi

$\mathrm{X}_{1} \quad$ : Cita Rasa

$\mathrm{X}_{2} \quad$ : Cara Penyajian

$\mathrm{X}_{3} \quad$ : Variasi Menu

\section{HASIL DAN PEMBAHASAN}

\section{Identitas Responden}

Responden berdasarkan jenis kelamin pria sebanyak 36 orang (36\%), wanita sebanyak 64 orang (64\%). Responden berdasarkan usia 17-21 tahun sebanyak 33 orang (23\%), 22-26 tahun sebanyak 14 orang (14\%), 27-31 tahun sebanyak 46 orang (46\%), 32-36 tahun sebanyak 9 orang (9\%), 37-42 tahun sebanyak 5 orang $(5 \%)$ dan $>42$ tahun sebanyak 3 orang (3\%). Responden berdasarkan pekerjaan Pegawai Negeri Sipil sebanyak 8 orang (8\%), ibu rumah tangga sebanyak 3 orang (3\%), pegawai perusahaan sebanyak 6 orang (6\%), wiraswasta sebanyak 45 orang (45\%) pelajar sebanyak 36 orang $(36 \%)$, dan guru les sebanyak 2 orang (2\%). Responden berdasarkan pendapatan perbulan $<1$ juta sebanyak 41 orang (41\%), 3,1 juta-5 Juta sebanyak 51 orang (51\%), 5,1 Juta-7 Juta sebanyak 3 orang (3\%), dan $>7$ Juta sebanyak 5 orang (5\%).

\section{Hasil Uji Analisis Regresi Berganda}

Uji analisis ini digunakan untuk mengetahui pengaruh variabel independen kualitas makanan (cita rasa, cara penyajian dan variasi menu) terhadap variabel dependen kesetiaan pelanggan pada tabel berikut ini: 


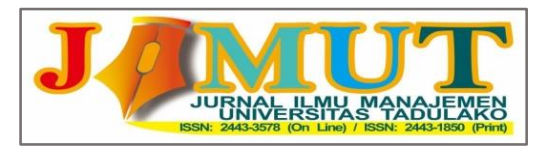

Vol. 6, No.3, September 2020, 222-231

Tabel 1. Regresi Linear Berganda

\begin{tabular}{|c|c|c|c|c|c|}
\hline \multicolumn{6}{|c|}{ Dependen Variabel Y = Kesetiaan Pelanggan } \\
\hline \multirow[t]{2}{*}{$\begin{array}{c}\text { Variabel } \\
\text { Dependen }\end{array}$} & \multicolumn{2}{|c|}{$\begin{array}{l}\text { Unstandardized } \\
\text { Coefficients }\end{array}$} & \multirow{2}{*}{$\begin{array}{c}\text { Standardized } \\
\text { Coefficients } \\
\text { Beta }\end{array}$} & \multirow[t]{2}{*}{$\mathrm{t}$} & \multirow{2}{*}{ Sig. $\mathrm{t}$} \\
\hline & B & Std. Error & & & \\
\hline (Constant) & 0,225 & 0,173 & & 0,117 & 0,907 \\
\hline $\begin{array}{l}\text { Cita Rasa } \\
\text { (X1) }\end{array}$ & 0,252 & 0,088 & 0,277 & 2,849 & 0,005 \\
\hline $\begin{array}{c}\text { Cara } \\
\text { Penyajian } \\
\text { (X2) }\end{array}$ & 0,252 & 0,083 & 0,285 & 3,044 & 0,003 \\
\hline $\begin{array}{c}\text { Variasi } \\
\text { Menu (X3) }\end{array}$ & 0,153 & 0,050 & 0,261 & 3,074 & 0,003 \\
\hline \multicolumn{3}{|c|}{ Multiple $\mathrm{R}=0,608$} & \multicolumn{2}{|c|}{$\mathrm{R}$ Square $=0,370$} & \\
\hline \multicolumn{3}{|c|}{ Adjusted R Square $=0,350$} & \multicolumn{2}{|c|}{ Sig. $F=0,000$} & \\
\hline \multicolumn{3}{|l|}{$\mathrm{F}=18,000$} & & & \\
\hline
\end{tabular}

Sumber : Data, diolah.

Berdasarkan hasil uji regresi pada Tabel 1 di atas, diperoleh persamaan regresi sebagai berikut: $Y=0,225+0,252\left(X_{1}\right)+0,252\left(X_{2}\right)+0,153\left(X_{3}\right)$

1. Nilai Konstanta sebesar 0,225, artinya jika kualitas makanan (cita rasa, cara penyajian, dan variasi menu) dianggap konstan atau tidak mengalami perubahan (bernilai 0), maka kesetiaan pelanggan pada Kedai Oishi Nadisha di Kota Palu.

2. Koefisien regresi variabel cita rasa sebesar 0,252 dan bertanda positif. Hal ini berarti jika setiap perubahan satu satuan pada cita rasa dengan asumsi semua variabel lainnya tetap, maka kesetiaan pelanggan pada Kedai Oishi Nadisha di Kota Palu mengalami perubahan sebesar 0,252.

3. Koefisien regresi variabel cara penyajian sebesar 0,252 dan bertanda positif. Hal ini berarti jika setiap perubahan satu satuan pada cara penyajian dengan semua asumsi variabel lainnya tetap, maka kesetiaan pelanggan pada Kedai Oishi Nadisha di Kota Palu mengalami perubahan sebesar 0,252.

4. Koefisien regresi variabel variasi menu sebesar 0,153 dan bertanda positif. Hal ini berarti jika setiap perubahan satu satuan pada variasi menu dengan semua asumsi variabel lainnya tetap, maka kesetiaan pelanggan pada Kedai Oishi Nadisha di Kota Palu mengalami perubahan sebesar 0,153.

\section{Pengujian Hipotesis Koefisien Deteriminasi Ganda (Uji F)}

Analisis regresi berganda dengan menggunakan uji F digunakan untuk menguji pengaruh secara serempak terhadap semua variabel, adapun hasil uji F pada tabel berikut: 


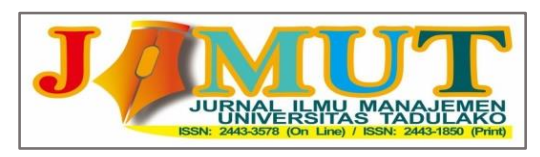

Vol. 6, No.3, September 2020, 222-231

Tabel 2. Hasil Uji Hipotesis Ganda (Uji F)

\begin{tabular}{llcrrrr}
\hline & Model & $\begin{array}{l}\text { Sum of } \\
\text { Squares }\end{array}$ & df & \multicolumn{1}{c}{$\begin{array}{c}\text { Mean } \\
\text { Square }\end{array}$} & F & Sig. \\
\hline 1 & Regression & 171.256 & 3 & 57.085 & 18.800 & $0.000^{\mathrm{a}}$ \\
& Residual & 291.494 & 96 & 3.036 & & \\
& Total & 462.750 & 99 & & &
\end{tabular}

Sumber : Data, diolah.

Berdasarkan Tabel 2 di atas diperoleh nilai sig yaitu 0,000 yang artinya nilai tersebut lebih kecil jika dibandingkan dengan nilai signifikansi sebesar 0,05, dengan demikian dapat disimpulkan bahwa variabel independen secara simultan yang terdiri dari: cita rasa, cara penyajian, dan variasi menu berpengaruh signifikan terhadap kesetiaan pelanggan pada Kedai Oishi Nadisha di Kota Palu, maka hipotesis penelitian ini diterima.

\section{Pengujian Hipotesis Koefisien Determinasi Parsial (Uji Parsial/Uji t)}

Uji t merupakan pengujian untuk menunjukkan pengaruh secara variabel bebas terhadap variabel terikat. Apabila nilai signifikansi lebih kecil dari 0,05 maka dapat disimpulkan bahwa variabel bebas secara parsial berpengaruh signifikan terhdapat variabel terikat.

Tabel 3. Hasil Uji Hipotesis Parsial (Uji t)

\begin{tabular}{|c|c|c|c|c|c|c|c|c|}
\hline \multirow{2}{*}{\multicolumn{2}{|c|}{ Model }} & \multicolumn{2}{|c|}{$\begin{array}{l}\text { Unstandardized } \\
\text { Cofficients }\end{array}$} & \multirow{2}{*}{$\begin{array}{c}\text { Standardized } \\
\text { Cofficients }\end{array}$} & \multirow[t]{2}{*}{$\mathrm{t}$} & \multirow[t]{2}{*}{ Sig. } & \multicolumn{2}{|c|}{ Collinearity Statistics } \\
\hline & & B & $\begin{array}{c}\text { Std } \\
\text { Error }\end{array}$ & & & & Tolerance & VIF \\
\hline 1 & Constant & 0.255 & 0.173 & & 0.117 & 0.907 & & \\
\hline & $\mathrm{X} 1$ & 0.252 & 0.088 & 0.277 & 2.849 & 0.005 & 0.695 & 1.438 \\
\hline & $\mathrm{X} 2$ & 0.252 & 0.083 & 0.285 & 3.044 & 0.003 & 0.750 & 1.334 \\
\hline & X3 & 0.153 & 0.050 & 0.261 & 3.074 & 0.003 & 0.908 & 1.101 \\
\hline
\end{tabular}

Sumber : Data, diolah.

Berdasarkan Tabel 3 di atas diketahui besarnya pengaruh masing-masing variabel independen secara parsial terhadap variabel dependen adalah sebagai berikut:

1. Hasil Pengujian Hipotesis Cita Rasa Terhadap Kesetiaan Pelanggan

Hasil yang diperoleh pada penelitian ini besarnya nilai sig $\mathrm{t}=0,005<\propto=0,05$, dengan demikian bahwa secara parsial variabel cita rasa berpengaruh signifikan terhadap kesetiaan pelanggan pada Kedai Oishi Nadisha di Kota Palu. Adapun besar pengaruh dari variabel ini adalah 25,2\%, maka hipotesis penelitian ini diterima.

2. Hasil Pengujian Hipotesis Cara Penyajian Terhadap Kesetiaan Pelanggan

Hasil yang diperoleh pada penelitian ini besarnya nilai sig $\mathrm{t}=0,003<\propto=0,05$, dengan demikian bahwa secara parsial variabel cara penyajian berpengaruh signifikan terhadap kesetiaan pelanggan pada Kedai Oishi Nadisha di Kota Palu. Adapun besar pengaruh dari variabel ini adalah adalah 25,2\%, maka hipotesis penelitian ini diterima. 


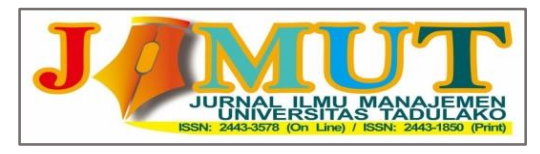

Vol. 6, No.3, September 2020, 222-231

3. Hasil Pengujian Hipotesis Variasi Menu Tethadap Kesetiaan Pelanggan

Hasil yang diperoleh pada penelitian ini besarnya nilai sig $\mathrm{t}=0,003<\propto=0,05$, dengan demikian bahwa secara parsial variabel variasi menu berpengaruh signifikan terhadap kesetiaan pelanggan pada Kedai Oishi Nadisha di Kota Palu. Adapun besar pengaruh dari variabel ini adalah adalah 25,2\%, maka hipotesis penelitian ini diterima.

\section{Pembahasan Hasil Penelitian}

1. Pengaruh Cita Rasa (X1) Terhadap Kesetiaan Pelanggan Pada Kedai Oishi Nadisha di Kota Palu

Berdasarkan hasil uji regresi, terbukti bahwa variabel cita rasa memengaruhi kesetiaan pelanggan pada Kedai Oishi Nadisha di Kota Palu, sedangkan dalam hasil uji t cita rasa menjadi dominan dengan hasil sebesar 0,252. Indikator yang dimasukan dalam penelitian ini yaitu, mempunyai tampilan makanan yang menarik, hal tersebut diciptakan oleh Kedai Oishi Nadisha bertujuan untuk menarik perhatian pelanggan dengan cara membuat sesuatu yang sudah ada menjadi hal yang menarik dan hal yang baru, yang dimana menu sushi dan ramen khas negara Jepang yang disajikan dengan perpaduan cita rasa makanan negara Indonesia. Selanjutnya indikator potongan makanan yang menggugah selera, indikator aroma makanan berbau sedap saat dihidangkan, dan indikator rasa makanan yang disajikan sesuai dengan kriteria makanan juga dilakukan di Kedai Oishi Nadisha dibuat bertujuan agar pelanggan yang melihat, mencium aroma makanan yang disajikan bisa menambah selera makan pelanggan. Secara keseluruhan cita rasa makanan berpengaruh terhadap kesetiaan pelanggan karna hal yang paling utama dalam memilih makanan untuk disantap adalah cita rasa, semakin nikmat atau enak cita rasa makanan yang disantap pelanggan, semakin lezat rasa makanan yang disajikn akan menimbulkan rasa kesetiaan pelanggan. Banyak usaha-usaha lain yang kurang memperhatikan beberapa hal item yang terdapat dalam cita rasa, padahal hal tersebut merupakan salah satu hal yang sangat berpengaruh dalam meningkatkan atau memepertahankan kesetiaan pelanggan. Penelitian ini sejalan dengan hasil penelitian Rahmaddiansyah, Fajri, dan Utami (2015) bahwa cita rasa berpengaruh secara signifikan terhadap kesetiaan pelanggan. Penelitian lain yang juga sejalan dengan penelitian ini yang dilakukan oleh Kristianto dan Andiwijaya (2018) bahwa bahwa cita rasa berpengaruh secara signifikan terhadap kesetiaan pelanggan.

2. Pengaruh Cara Penyajian (X2) Terhadap Ksetiaan Pelanggan Pada Kedai Oishi Nadisha di Kota Palu

Berdasarkan hasil uji regresi, terbukti bahwa variabel cara penyajian mempengaruhi kesetiaan pelanggan pada Kedai Oishi Nadisha di Kota Palu, sedangkan dalam hasil uji t cara penyajian menjadi dominan dengan hasil sebesar 0,252. Indikator yang digunakan yaitu terdapat perpaduan warna yang menarik. Dimana hal tersebut dilakukan dengan cara menggunakan berbagai macam saos, atau mayones dan tambahan toping pada makanan seperti abon sapi, abon ayam dan sosis, pada makanan yang ditujukan untuk membuat tampilan makanan menjadi lebih menarik dan dapat menambah selera makan.

Indikator selanjutnya yaitu makanan tertata rapi, sebelum makanan dihidangkan kepada pelanggan, makanan di tata sedemikian rapi, untuk menu sushi di buat dengan potongan yang sama rata dan sama besar, dan di tata berjejer diatas piring saji dan untuk menu ramen disajikan dengan toping abon sapi, ataupun sosis diatas mie yang sudah dipadukan dengan kuah sehingga terlihat sangat menarik. Kedai Oishi Nadisha berhasil membuat pelanggan menyukai cara penyajian yang dilakukan, hal tersebut dibuktikan dengan prilaku pelanggan memotret makanan yang disajikan kemudian di unggah ke akun sosial media milik pribadi pelanggan baru setelah itu di santap oleh 


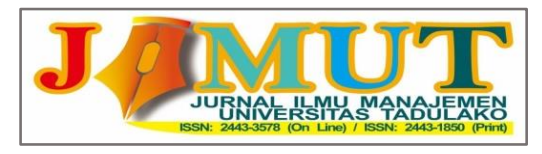

Vol. 6, No.3, September 2020, 222-231

pelanggan. Hal tersebut dilakukan pelanggan, karna pelanggan sangat senang dengan cara penyajian makanan di Kedai Oishi Nadisha yang rapi. Cara penyajian makanan merupakan hal yang pertama dilihat dan dinilai oleh pelanggan sebelum makanan tersebut disantap. Dengan adanya cara penyajian yang menarik, pelanggan merasa senang dan menambah nafsu makan pelanggan, hal tersebut terjadi karna indera pengelihatan manusia yaitu mata menilai bahwa makanan yang dihidangkan sangat indah, sehingga otak merespon bahwa makanan yang disajikan bisa menambah nafsu makan. hal tersebut dapat membuat pelanggan setia karna pelanggan merasa senang dan menilai bahwa selain makanan yang disantap bercita rasa lezat dan makanan tersebut mempunyai cara penyajian yang indah ataupun menarik. Penelitian ini sejalan dengan hasil penelitian Arianti, Taslim, dan Fitriani (2012) bahwa cara penyajian berpengaruh secara signifikan terhadap kesetiaan pelanggan.

3. Pengaruh Variasi Menu (X3) Terhadap Kesetiaan Pelanggan Pada Kedai Oishi Nadisha di Kota Palu

Berdasarkan hasil uji regresi, terbukti bahwa variabel variasi menu memengaruhi kesetiaan pelanggan pada Kedai Oishi Nadisha di Kota Palu, sedangkan dalam hasil uji t variasi menu menjadi dominan ketiga sebesar 0,153 setelah cita rasa dan cara penyajian. Indikator yang digunakan yaitu tersedia sushi dengan variasi digoreng, hal tersebut sangat disukai pelanggan karna kebanyakan pelanggan selalu memesan menu sushi dengan variasi di goreng karna tidak banyak pelanggan Kedai Oishi Nadisha yang menyukai sushi yang tidak di goreng, pelanggan Kedai Oishi Nadisha menyukai variasi sushi yang digoreng karna dengan adanya variasi sushi di goreng, rasa sushi tersebut menjadi lebih garing ketika di kunyah dibandingkan dengan sushi yang tidak di goreng. Indikator selanjutnya yaitu tersedia sushi dengan berbagai macam variasi isian yaitu sosis, daging ayam, tuna, kepiting, udang, daging sapi, abon ayam, dan abon sapi, hal tersebut sangat disukai pelanggan karna tersedianya berbagai macam pilihan isian yang ditawarkan, pelanggan bebas memilih sesuka hati dan sesuai selera pelanggan dan membuat pelanggan tidak merasa jenuh dengan adanya berbagai macam variasi menu yang ditawarkan.

Sejauh ini para pesaing yang menjual produk yang sama seperti yang ditawarkan Kedai Oishi Nadisha di Kota Palu belum menyediakan variasi menu yang dilakukan seperti Kedai Oishi Nadisha, sehingga pelanggan tetap memilih Kedai Oishi Nadisha, dan akan kembali lagi untuk melakukan pembelian dan menciptakan kesetiaan pelanggan.Penelitian ini sejalan dengan hasil penelitian Hasanah dan Hari (2016) bahwa variasi menu berpengaruh signifikan terhadap kesetiaan pelanggan.

\section{KESIMPULAN DAN SARAN}

Berdasarkan hasil penelitian yang telah dijelaskan, maka diperoleh kesimpulan mengenai pengaruh kualitas makanan terhadap kesetiaan pelanggan pada Kedai Oishi Nadisha di Kota Palu yaitu:

1. Kualitas makanan yang terdiri dari cita rasa, cara penyajian, dan variasi menu secara simultan berpengaruh signifikan terhadap kesetiaan pelanggan pada Kedai Oishi Nadisha di Kota Palu.

2. Dimensi cita rasa secara parsial berpengaruh signifikan terhadap kesetiaan pelanggan pada Kedai Oishi Nadisha di Kota Palu.

3. Dimensi cara penyajian secara parsial berpengaruh signifikan terhadap kesetiaan pelanggan pada Kedai Oishi Nadisha di Kota Palu.

4. Dimensi variasi menu secara parsial berpengaruh signifikan terhadap kesetiaan pelanggan pada Kedai Oishi Nadisha di Kota Palu.

Penelitian yang telah dilakukan memiliki beberapa saran yaitu: (1) Diharapkan Kedai Oishi Nadisha dapat menjaga dan mempertahankan kualitas makanan mulai dari cita rasa, cara penyajian, 


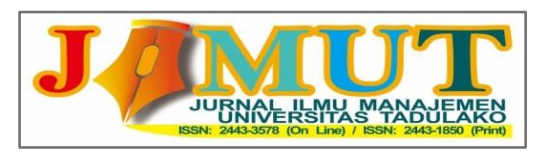

Vol. 6, No.3, September 2020, 222-231

dan variasi menu makanan yang disajikan kepada pelanggan, dengan cara penggunaan bahan baku pilihan, dan segar serta takaran bumbu yang konsisten dalam masakan, dan diharapkan Kedai Oishi Nadisha juga agar lebih berinovasi serta inovatif dalam menyajikan menu-menu yang tersedia. (2) demi meningkatkan kesetiaan pelanggan dan memperluas usaha demi mencapai sebuah keuntungan, disarankan pihak Kedai Oishi Nadisha membuka cabang di Kota Palu yang lebih strategis, mudah untuk dijangkau konsumen atau mendekati pangsa pasar, sehingga pelanggan yang sudah setia tidak berpaling ke pesaing yang lebih dekat dari jangkauan pelanggan dan menawarkan produk yang sejenis. (3) Peneliti selanjutnya disarankan dapat menambahkan variabel lain yang belum disertakan dalam model penelitian ini seperti harga, dan kesehatan makanan.

\section{REFERENSI}

Knight, J.B., Kotschevor, L. (2000). Quality Food Production Planning and Management: 3rd Edition. Canada: Simultaneously.

Winata, A. S., \& Gienardy, R. (2013). Analisa Persepsi Konsumen Terhadap Harga, Kualitas Produk, dan Suasana di Cafe My Kopi O. Jurnal Hospitality dan Manajemen Jasa, 1(2).

Kotler, Philip dan Kevin Lane Keller, (penyuntingan), (2008). Manajemen Pemasaran, Jilid 1,Penerbit Erlangga. Jakarta.

Laksana, Fajar, (2008). Manajemen Pemasaran Pendekatan Praktis, Edisi Pertama Yogyakarta, Graha Ilmu.

Feigenbaum A.V, (Penyuntingan), (1996) Total Quality Control, Penerbit Erlangga Jakarta.

Hurriyati, Ratih, (2005). Bauran Pemasaran dan Loyalitas Konsumen, Cv.Alfabeta Bandung.

Wahyuni, Sulistiyowati, Khamim, (2015). Pengendalian Kualitas. Yogyakarta Graha Ilmu.

Kurniawan, Albert, (2014). Metode Riset Untuk Ekonomi dan Bisnis, Cv Alfabeta Bandung.

Sugiyono, 2014. Metode Penellitian Bisnis (Pendekatan Kuantitatif, Kualitatif dan R\&D), Alfabeta. Bandung.

Rahmaddiansyah, Fajri, dan Cut Vania Utami (2015). Analisis Loyalitas Konsumen Terhadap Minuman Kopi Robusta di Kota Banda Aceh. Argisep Vol.16 No.2.

Kristianto dan Andiwijaya. 2018. Pengaruh kualitas, harga, dan pengalaman pelanggan terhadap loyalitas pelanggan pada Rumah Makan Leko. Jurnal AGORA Vol. 6, No. 1.

Hasanah dan Harti. (2012). Pengaruh keragaman menu, harga dan kualitas pelayanan terhadap loyalitas pelanggan dengan kepuasan sebagai variabel intervening pada Waroeng "SS" (Spesial Sambel) Surabaya. Vol.1 No.1 